\title{
Valor nutricional e características químicas e físicas de frutos de murici-passa (Byrsonima verbascifolia)
}

\author{
Nutritional value and chemical and physical chacacteristics of dried murici fruits (Byrsonima verbascifolia)
}

\author{
Marília Mendonça GUIMARÃES ${ }^{1}$, Maria Sebastiana SILVA ${ }^{2 *}$
}

\begin{abstract}
Resumo
Estudos sobre o valor nutricional dos frutos do Cerrado e de seus produtos contribuem para utilização dos alimentos regionais na alimentação humana. Este trabalho teve por objetivo avaliar a composição química, física e microbiológica dos frutos de murici-passa e in natura. O processamento do Murici-Passa (MP) foi realizado em três repetições (MP1, MP2 e MP3), utilizando-se a desidratação osmótica seguida de secagem em estufa com circulação forçada de ar. Analisou-se a composição centesimal, atividade de água, $\mathrm{pH}$ e sólidos solúveis dos frutos de murici-passa e in natura. Os dados foram analisados por meio do coeficiente de variação, análise de variância (ANOVA) e Teste de Tukey $(\mathrm{p}<0,05)$. Os frutos desidratados perderam entre 63,00 e 68,00\% de água, concentrando os teores de macronutrientes, energia e sólidos solúveis em relação ao fruto in natura. Os teores de atividade de água variaram entre 0,78 e 0,85 , caracterizando o murici-passa como produto seco de umidade intermediária. $\mathrm{O}$ pH permaneceu abaixo de 4,50 para os frutos desidratados e in natura. O murici-passa apresentou condições microbiológicas satisfatórias para consumo. Concluindo, o valor nutricional do murici-passa evidencia um alimento rico em fibras e sua produção pode contribuir com a valorização dos alimentos regionais.

Palavras-chave: murici-passa; desidratação; avaliação química; valor nutricional.
\end{abstract}

\begin{abstract}
Research on the nutritional value of the Cerrado (vast tropical savanna ecoregion of Brazil) fruits and their derivative products contribute to the use of regional products in human nourishment. This work aimed at evaluating the chemical, physical, and microbiological composition of murici in natura and murici dried fruits. The fruits were processed in three repetitions (MP1, MP2, MP3) using the osmotic dehydration followed by drying in a forced air circulation oven. The centesimal composition, water activity, $\mathrm{pH}$, and soluble solids of murici dried and murici in natura were analyzed. The data were analyzed by the variation coefficient, the variance analysis, and the Tukey test $(\mathrm{p}<0,05)$. The dehydrated fruits lost about 63 to $68 \%$ of water concentrating their macronutrients, their energy, and their soluble solids when compared to the murici in natura. Water activity varied from 0,78 to 0,85 characterizing the dried murici as a dry product with intermediate moisture. The $\mathrm{pH}$ remained below 4,5 for both dehydrated and in natura fruits. The dried murici fruit presented satisfactory consumption microbiological conditions. It can be concluded that the nutritional value of the dried murici fruit indicates a fiber-rich food, and its production can contribute to the value of regional food.
\end{abstract}

Keywords: dried murici; dehydration; chemical evaluation; nutritional value.

\section{Introdução}

O murici (Byrsonima ssp., Malpighiaceae) é um fruto do Cerrado consumido principalmente in natura, sendo encontrado de dezembro a março, nas regiões serranas do Sudeste, nos cerrados de Mato Grosso e Goiás e no litoral do Norte e Nordeste do Brasil. Quando maduro, apresenta-se amarelado, com diâmetro de 1,5 a $2 \mathrm{~cm}$ e um forte odor semelhante a queijo rançoso (REZENDE; FRAGA, 2003; ALVES; FRANCO, 2003). Sua comercialização se restringe às feiras livres e mercados locais. A polpa é carnosa e macia, podendo ser consumida in natura ou sob a forma de sucos, geléias, sorvetes e licores (ALVES; FRANCO, 2003).
Há poucos estudos sobre as técnicas agronômicas adequadas para o cultivo e propagação desta frutífera (USP, 2007), assim como o seu potencial de utilização na alimentação humana, o que evidencia a importância de pesquisas sobre o valor nutricional do murici, bem como de produtos derivados deste fruto de sabor e aroma exóticos.

A desidratação dos frutos para a obtenção do murici-passa contribui para a preservação do produto, concentra o conteúdo de macronutrientes e possibilita sua adição em formulações, ressaltando a qualidade sensorial e nutricional de alimentos.

Recebido para publicação em 23/6/2007

Aceito para publicação em 28/11/2007 (002583)

${ }^{1}$ Faculdade de Nutrição, Universidade Federal de Goiás - UFG, Rua 227, Qd. 68, s/n., Setor Leste Universitário, CEP 74605-080, Goiânia - GO, Brasil,

E-mail:mg.marilia@bol.com.br

${ }^{2}$ Faculdade de Educação Física, Universidade Federal de Goiás - UFG, Campus Samambaia - Rodovia Goiânia/Nerópolis, Km 12, CP 131, CEP 74001-970, Goiânia - GO,

Brasil,E-mail: mssilva@fanut.ufg.br

${ }^{*}$ A quem a correspondência deve ser enviada 
Assim, este trabalho tem por objetivo avaliar a composição química, física e microbiológica dos frutos de murici desidratados e in natura.

\section{Material e métodos}

\subsection{Processamento do murici-passa}

Os frutos de murici foram colhidos nos meses de janeiro e fevereiro no município de Porangatu - GO, armazenados em embalagem de polietileno, resfriados a $8{ }^{\circ} \mathrm{C}$ até o momento do processamento.

Os frutos foram selecionados, lavados em água corrente para a eliminação de sujidades e desinfetados em solução de hipoclorito de sódio a 200 ppm (Anhembi) durante 15 minutos com posterior enxágüe, conforme instrução do fabricante. Os frutos maduros, de coloração amarelada e tamanho uniforme, foram processados para a elaboração do murici-passa. O processamento do murici-passa foi realizado em três repetições (MP1, MP2, MP3), seguindo o fluxograma descrito na Figura 1.

Após a higienização, os frutos in natura foram cortados manualmente, utilizando-se faca com lâmina de inox, e imersos em solução antioxidante de vitamina C (Synth), proporção 1:2 (fruto:solução), na concentração de $7,5 \mathrm{mg} \cdot 100^{-1} \mathrm{~mL}$, para prevenir reação enzimática de escurecimento. Posteriormente, foram colocados em solução osmótica de sacarose (Pérola) concentrada a $55^{\circ}$ Brix na proporção de $1: 2$ (fruto:solução) a $70{ }^{\circ} \mathrm{C}$ por 40 minutos. Em seguida, retiraram-se os frutos da solução osmótica com o auxílio de peneira de inox, submetendo-os a secagem em estufa com circulação forçada de ar (Marconi, Modelo MA - 035) a $70{ }^{\circ} \mathrm{C}$ durante 6 horas.

A estabilização da temperatura e umidade dos frutos desidratados foi realizada após a retirada da estufa. Os frutos desidratados foram colocados em recipiente de polietileno coberto com tecido de algodão. Após 24 horas, os frutos desidratados foram embalados a vácuo em sacos de polietileno de baixa permeabilidade (Cosvac), com posterior congelamento em freezer vertical a $-20{ }^{\circ} \mathrm{C}$.

\subsection{Análise da composição centesimal}

Os frutos de murici-passa e in natura foram analisados quanto aos teores de umidade (INSTITUTO ADOLFO LUTZ, 2005) e Resíduo Mineral Fixo (RMF) (AOAC, 1992) por meio de análise gravimétrica, proteína pelo método de Kjeldahl (1883 apud AOAC, 1992), lipídios totais (BLIGH; DYER, 1959), carboidratos totais por diferença e fibra alimentar pelo método enzimático-gravimétrico (INSTITUTO ADOLFO LUTZ, 2005).

\subsection{Outras análises}

Os frutos desidratados e in natura também foram submetidos em triplicata às análises de atividade de água (Aw), pH e sólidos solúveis de acordo com as metodologias descritas em Instituto Adolfo Lutz (2005).

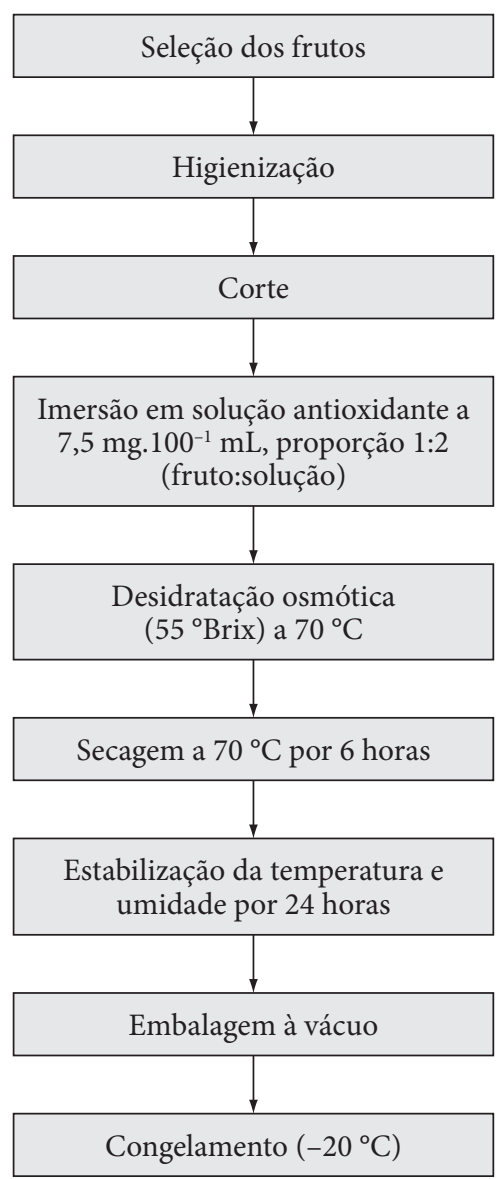

Figura 1. Fluxograma de processamento do murici-passa.

\subsection{Análise microbiológica}

As análises microbiológicas realizadas no murici-passa foram contagem de coliformes a $45^{\circ} \mathrm{C}$ e presença de Salmonella sp. em $25 \mathrm{~g}$ de acordo com as normas estabelecidas pela Resolução RDC $n^{\circ} 12$ que regulamenta os Padrões Microbiológicos para Alimentos (BRASIL, 2001). As análises microbiológicas seguiram os procedimentos descritos pela American Public Health Association (APHA, 2001).

\subsection{Análise estatística}

Os resultados das análises químicas e físicas dos frutos de murici in natura e murici-passa foram expressos por meio de média, desvio padrão e submetidos à análise de variância (ANOVA) e comparação das médias pelo Teste de Tukey (nível de significância, $\mathrm{p}<0,05)$, utilizando-se o software Instat.

\section{Resultados e discussão}

A caracterização nutricional dos frutos de murici-passa e in natura foi realizada considerando-se os teores de umidade, carboidratos, lipídios, proteínas e RMF, conforme apresentado na Tabela 1. Os resultados de umidade indicaram que os frutos de murici desidratados perderam em média 63,00 a 68,00\% de água em relação à umidade inicial. Apesar da análise estatística dos dados de umidade não demonstrar diferenças entre as repetições MP1 e MP2, apenas MP1 apresentou teor de umidade 
de acordo com os parâmetros estabelecidos pela legislação para produtos desidratados. A Resolução CNNPA (Comissão Nacional de Normas e Padrões para Alimentos) no 12 de 1978 da Agência Nacional de Vigilância Sanitária (ANVISA) caracteriza como fruta seca produtos com umidade inferior a $25,00 \%$, sendo este um fator protetor ao desenvolvimento de microorganismos deteriorantes e patogênicos (BRASIL, 1978).

O murici é um fruto pequeno com $10,08 \pm 1,92$ e $11,93 \pm 2,34 \mathrm{~mm}$ de comprimento e diâmetro, respectivamente (GUSMÃO; VIEIRA; FONSECA JÚNIOR, 2005) e sua parte não comestível representa 46,50\% do fruto (IBGE, 1996). Devido às características biométricas do murici, teores de umidade muito baixos do produto desidratado podem comprometer a textura, tornando-os mais rijos, além de diminuir a porcentagem de polpa e a sua viabilidade econômica. Segundo Alves (2003), o teor de umidade remanescente é o principal fator que influencia na textura da fruta seca. Cada tipo de fruta apresenta uma umidade crítica, acima da qual a fruta está sujeita à deterioração por microorganismos.

No que se refere aos teores de proteínas e lipídios (Tabela 1), não houve diferença significativa entre as repetições. Os valores encontrados para carboidratos demonstram que as repetições MP1 e MP2 não diferiram entre si, mas apresentaram teores maiores que a MP3 $(\mathrm{p}<0,05)$. Quanto ao conteúdo de RMF, foram observados valores maiores na repetição MP3 $(p<0,05)$, diferindo de MP1 e MP2. Em relação aos frutos de murici in natura, os resultados do presente trabalho foram similares aos encontrados na tabela de composição de alimentos (IBGE, 1996).

Em relação à atividade de água, as repetições MP1, MP2 e MP3 não apresentaram diferenças significativas (Tabela 2), caracterizando alimentos com umidade intermediária (Aw entre $0,60$ e 0,85$)$. Normalmente, as frutas secas encontram-se neste grupo, representando segurança do ponto de vista sanitário onde mofo e leveduras podem desenvolver-se, mas não produzem toxinas (ORDÓÑHEZ et al., 2005). De acordo com Jay (1991) os valores de atividade de água para frutas secas podem variar

Tabela 1. Composição centesimal dos frutos de Murici-Passa (MP) e in natura (M) (g.100 g $\mathrm{g}^{-1}$.

\begin{tabular}{|c|c|c|c|c|}
\hline & MP1 & MP2 & MP3 & $\mathrm{M}$ \\
\hline Umidade & $23,97 \pm 0,03^{a}$ & $25,60 \pm 0,31^{\mathrm{a}}$ & $28,24 \pm 0,19^{b}$ & $75,87 \pm 2,00^{c}$ \\
\hline Carboidratos & $66,16 \pm 0,10^{a}$ & $64,96 \pm 0,16^{\mathrm{a}}$ & $62,06 \pm 0,14^{\mathrm{b}}$ & $19,62 \pm 1,82^{c}$ \\
\hline Lipídios & $7,11 \pm 0,09^{\mathrm{a}}$ & $6,85 \pm 0,17^{\mathrm{a}}$ & $6,82 \pm 0,17^{\mathrm{a}}$ & $3,02 \pm 0,26^{\mathrm{b}}$ \\
\hline Proteínas & $1,72 \pm 0,08^{\mathrm{a}}$ & $1,65 \pm 0,03^{\mathrm{a}}$ & $1,73 \pm 0,05^{\mathrm{a}}$ & $0,86 \pm 0,00^{b}$ \\
\hline $\mathrm{RMF}^{2}$ & $1,04 \pm 0,01^{\mathrm{a}}$ & $0,98 \pm 0,03^{\mathrm{a}}$ & $1,16 \pm 0,01^{b}$ & $0,63 \pm 0,04^{c}$ \\
\hline
\end{tabular}

${ }^{1}$ Médias com letras iguais na mesma linha não diferem significativamente entre si ( $\mathrm{p}<0,05)$; $\mathrm{e}^{2}$ resíduo mineral fixo. de 0,51 a 0,89 . Alves (2003) encontrou teores de atividade de água de $0,824 \mathrm{em}$ acerolas desidratadas a $60^{\circ} \mathrm{C}$ durante 8 horas, utilizando como pré-tratamento desidratação osmótica com solução binária sacarose-água.

Os valores de $\mathrm{pH}$ diferiram entre as repetições, mas não houve variação substancial $(p>0,05)$ entre o do murici in natura e da repetição MP1 (Tabela 2). Todos os produtos desidratados permaneceram com $\mathrm{pH}$ abaixo de 4,50 , classificados com muito ácidos (AZEREDO et al., 2004), o que confere fator protetor ao produto, além de exercer efeito sinérgico aos teores de atividade de água (AZEREDO; BRITO, 2004).

As repetições MP1, MP2 e MP3 não diferiram significativamente quanto aos sólidos solúveis totais. Os frutos in natura apresentaram valores de sólidos solúveis significativamente inferiores aos frutos secos $(\mathrm{p}<0,05)$ (Tabela 2). O teor de sólidos solúveis totais é um importante fator de qualidade quanto ao sabor. O conteúdo médio superior a $9 \%$ é bastante desejável do ponto de vista comercial (MENEZES et al., 2001). Assim, o aumento do conteúdo de sólidos solúveis na fruta pela desidratação osmótica pode favorecer sua comercialização.

O valor energético do murici-passa triplicou em relação ao murici in natura (Figura 2), o que pode ser explicado pela incorporação de sólidos solúveis durante a desidratação osmótica e pela perda de água ocorrida durante o processo de secagem. Segundo Matos (2005), a técnica de desidratação realça o sabor das frutas, aumenta seu valor energético, representando uma fonte concentrada de macronutrientes e energia (Tabela 1; Figura 2), com destaque para o aumento no teor de fibras.

Devido ao fato da MP1 apresentar teor de umidade de acordo com os parâmetros legais (BRASIL, 1978) para frutas

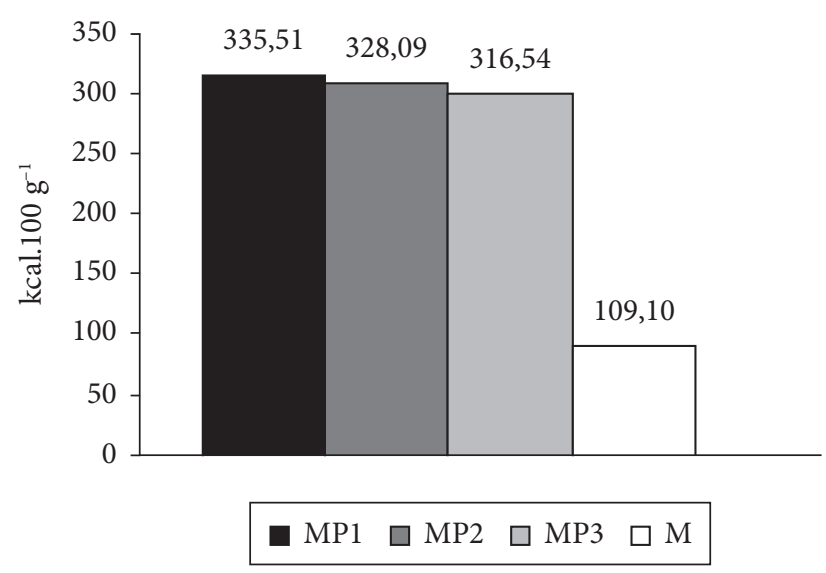

Figura 2. Valor energético estimado ( $\left.\mathrm{kcal} 100 \mathrm{~g}^{-1}\right)$ de frutos de murici-passa e in natura.

Tabela 2. Atividade de água, $\mathrm{pH}$ e sólidos solúveis dos frutos de murici-passa e in natura.

\begin{tabular}{lrrrr}
\hline & MP1 & MP2 & MP3 & \multicolumn{1}{c}{ M } \\
\hline Atividade de água (Aw) & $0,83 \pm 0,05^{\mathrm{a}}$ & $0,78 \pm 0,04^{\mathrm{a}}$ & $0,85 \pm 0,03^{\mathrm{a}}$ & $0,98 \pm 0,00^{\mathrm{b}}$ \\
$\mathrm{pH}$ & $3,40 \pm 0,01^{\mathrm{a}}$ & $3,24 \pm 0,01^{\mathrm{b}}$ & $3,34 \pm 0,03^{\mathrm{c}}$ & $3,42 \pm 0,03^{\mathrm{a}}$ \\
Sólidos solúveis ( ${ }^{\circ}$ Brix) & $42,82 \pm 0,07^{\mathrm{a}}$ & $42,82 \pm 0,14^{\mathrm{a}}$ & $42,98 \pm 0,11^{\mathrm{a}}$ & $10,67 \pm 0,58^{\mathrm{b}}$ \\
\hline
\end{tabular}

${ }^{1}$ Médias com letras iguais na mesma linha não diferem significativamente entre si $(\mathrm{p}<0,05)$. 
secas, apenas esta repetição foi submetida à análise de fibras. $\mathrm{O}$ valor médio de $26,04 \pm 0,38 \mathrm{~g} .100 \mathrm{~g}^{-1}$ foi superior ao teor mínimo estabelecido pela Portaria $\mathrm{n}^{\circ} 27$ de 13 de janeiro de 1998 da ANVISA (BRASIL, 1998), ou seja, 6 g. $100 \mathrm{~g}^{-1}$ de fibra, para classificar um alimento sólido como sendo de alto teor de fibra alimentar. Portanto, o processo de secagem proporcionou também um aumento no teor de fibras em relação ao murici in natura (2,2 g.100 g $\left.\mathrm{g}^{-1}\right)$ (IBGE, 1996).

No que se refere à avaliação microbiológica, os resultados indicaram que as repetições do processamento de murici-passa estavam de acordo com os padrões estabelecidos pelo item 1c do Regulamento Técnico da Resolução (RDC) no 12 (BRASIL, 2001), ou seja, a contagem de coliformes termotolerantes foi inferior ao valor máximo permitido $\left(<1,0 \times 10^{2} \mathrm{UFC}^{-g^{-1}}\right)$ e a pesquisa de Salmonella indicou ausência em $25 \mathrm{~g}$ dos frutos desidratados.

Os coliformes totais e fecais colonizam o trato intestinal de animais de sangue quente, incluindo os humanos e podem contaminar os alimentos por meio de falhas no aspecto higiênico durante o processamento (SILVA JÚNIOR, 2001). Já a Salmonella pode estar presente em frutos, dada a possibilidade do contato com matéria fecal animal durante seu cultivo (AGÊNCIA PORTUGUESA DE SEGURANÇA ALIMENTAR, 2007). Portanto, ambos os microorganismos são empregados como indicadores de qualidade higiênico-sanitária na manipulação de alimentos (SILVA JÚNIOR, 2001).

Neste estudo, os frutos de murici-passa, classificados como alimentos muito ácidos e de umidade intermediária, apresentaram resultados satisfatórios nas análises microbiológicas, demonstrando que o sinergismo entre a atividade de água e o $\mathrm{pH}$ associado às boas condições higiênico-sanitárias de manipulação e ao tratamento térmico adequado foram eficazes para a segurança microbiológica do produto desidratado.

\section{Conclusões}

- As repetições MP1, MP2 e MP3 caracterizam um produto seco de umidade intermediária;

- O murici-passa apresentou-se próprio para consumo, de acordo com os resultados das análises microbiológicas;

- Os valores de $\mathrm{pH}$ e Aw das repetições de murici-passa podem apresentar sinergismo e conferir proteção microbiológica ao produto;

- O murici-passa evidencia um alimento rico em fibras e com conteúdo de carboidrato, proteína e lipídio maior que o fruto in natura; $\mathrm{e}$

- As características nutricionais, físicas e químicas encontradas nos frutos de murici-passa contribuem com os estudos de valorização dos alimentos regionais na alimentação humana.

\section{Referências bibliográficas}

ALVES, D. G. Obtenção de acerola (Malpighia puncifolia L.) em passa utilizando processos combinados de desidratação osmótica e secagem. Campinas, 2003. 164p. Tese - (Doutorado em Engenharia de Alimentos) - Faculdade de Engenharia de Alimentos, Universidade Estadual de Campinas - UNICAMP.

ALVES, G. L.; FRANCO, M. R. B. Headspace gas chromatographymass spectrometry of volatile compounds in murici (Byrsonima crassifolia L. Rich). Journal of Chromatography A, v. 985, n. 4, p. 297-301, 2003.

AGÊNCIA PORTUGUESA DE SEGURANÇA ALIMENTAR. Riscos biológicos. Disponível em: <http://www.agenciaalimentar.pt>. Acesso em: 24 Maio 2007.

APHA - American Public Health Association. Compendium of Methods for the Microbiological Examination of Foods. 4 ed. Washington: APHA, 2001.

AOAC - Association of Official Agricultural Chemists. Official methods of analysis. $10 \mathrm{ed}$. Washington, 1992. 1115p.

AZEREDO, H. M. C.; BRITO, E. S. Tendências em Conservação de Alimentos. In: AZEREDO, H. M. C. Fundamentos de Estabilidade de Alimentos. Fortaleza: Embrapa Agroindústria Tropical, 2004. cap. 6, p. 135-150.

AZEREDO, H. M. C. et al. Alterações Microbiológicas Durante a Estocagem. In: AZEREDO, H. M. C. Fundamentos de Estabilidade de Alimentos. Fortaleza: Embrapa Agroindústria Tropical, 2004. cap. 1, p. 20-35.

BLIGH, E, G.; DYER, W. J. A rapid method of total lipid extraction and purification. Canadian Journal of Biochemistry and Physiology, v. 37, n. 8, p. 911-917, 1959.

BRASIL. ANVISA - Agência Nacional de Vigilância Sanitária. Resolução RDC n 12, de 02 de janeiro de 2001. Regulamento técnico sobre os padrões microbiológicos para alimentos. Diário Oficial da União, Brasília, 02 de janeiro de 2001. Disponível em: $<$ http://e-legis.anvisa.gov.br/leisref/public/showAct.php?id=144>. Acesso em: 05 de Jan. de 2006.

. Portaria n² 27, de 13 de janeiro de 1998. Regulamento Técnico sobre a Informação Nutricional Complementar. Diário Oficial da União, Brasília, 16 de janeiro de 1998. Disponível em: <http://elegis.anvisa.gov.br/leisref/public/showAct.php?id=97>. Acesso em: 03 Set. 2006.

Resolução CNNPA n. 12, de 1978. Normas Técnicas Especiais. Diário Oficial da União, Brasília, 23 de julho de 1978. Disponível em: <http://e-legis.anvisa.gov.br/leisref/public/showAct. php?id=16216\&word $>$. Acesso em: 07 Maio 2006.

GUSMÃO, E.; VIEIRA, F. A.; FONSECA JÚNIOR, E. M. Biometria de frutos e endocarpos de murici (Byrsonima verbascifolia Rich. ex A. Juss.). Cerne, v. 12, n. 1, p. 84-91, 2006.

INSTITUTO ADOLFO LUTZ. Normas analíticas do Instituto Adolfo Lutz. Métodos físico-químicos para análise de alimentos. 4. ed. Brasília: Ministério da Saúde, Agência Nacional de Vigilância Sanitária, 2005. 1018 p. (Série A - Normas e Manuais Técnicos).

IBGE - Instituto Brasileiro de Geografia e Estatística. Estudo nacional de despesa familiar. Tabelas de composição de alimentos. 4 ed. Rio de Janeiro: IBGE, 1996. 137 p.

JAY, J. M. Microbiologia Moderna de Los Alimentos. 4 ed. Zaragoza: Acribia, 2002. 615p.

MATOS, E. H. S. F. Sistema de Brasileiro de Respostas Técnicas. Brasília: Ministério de Ciência e Tecnologia, 2005. p. 1-4.

MENEZES, J. B. et al. Armazenamento de dois genótipos de melão amarelo sob condições ambiente. Horticultura Brasileira, v. 19, n. 1, p. 42-49, 2001. 
ORDONHEZ, J. A. Conservação de alimentos com base na modificação do $\mathrm{pH}$, da atmosfera e da atividade de água. Evaporação e desidratação. In: . Tecnologia de Alimentos. v. 1, Cap. 11. Porto Alegre: Artmed, 2005.

REZENDE, C. M.; FRAGA, S. R. Chemical and aroma determination of the pulp and seeds of murici (Byrsonima crassifolia L.). Journal Brazilian Chemistry Society, v. 14, n. 3, p. 425-428, 2003.
SILVA JÚNIOR, E. A. Critérios microbiológicos para interpretação de laudos. In:_. Manual de controle higiêncio-sanitário em alimentos. 4. ed. São Paulo: Varela, 2001. cap. 39, p. 333-343.

USP - Universidade de São Paulo. Biblioteca Virtual do Estudante de Língua Portuguesa. Disponível em: <http://www.bibvirt.futuro. usp.br/textos/didaticos_e_tematicos/frutas_no_brasil $>$. Acesso em: 28 Mar. 2007. 